\title{
EXPERIMENTAL FOLIC ACID DEFICIENCY DUE TO ADMINISTRATION OF AMINOPTERIN IN MAN I. CLINICAL PICIURE
}

\author{
KATASHI INOUYE, TETSUO TAKEUCHI, AND RYOTA EGUCHI \\ Department of Internal Medicine, School of Medicine, \\ Kyoto University, Sakyo-ku, Kyoto
}

(Received April 3, 1956)

\begin{abstract}
Many folic acid derivatives which antagonize folic acid in the growth of micro-organisms have been synthesized and the actions of these folic acid antimetabolites have been studied in various animals. Aminopterin (Apt), one of the most potent folic acid antimetabolites (1), has been tried for the treatment of leukemia (6-9), since it has been found that folic acid, which is contained in large quantities both in malignant tumors (2) and in immature leukocytes (3), worsens such conditions as breast cancer of the mouse (4) and human leukemias (5). Administration of Apt in animals is known to produce various manifestations common to those observed in animals fed a folic aciddeflcient diet $(20-24)$. In addition, many of the toxic reactions appearing in leukemic patients following treatment with Apt are included in those manifestations of dietary folic acid deficiency in animals. Furthermore, the high folic acid levels in blood (determined microbiologically with Lactobacillus casei) observed in acute myelogenous leukemia have been found by the present authors to be lowered following the administration of Apt tried for the treatment of this disease.

These facts suggest the possibility of inducing an experimental folic acid deficiency in man by administration of Apt. Thus an attempt was made in the present experiment to study the action of Apt in healthy human subjects, when variations in the blood folic acid level together with various clinical manifestations were used as the criteria for judging a state of folic acid deficiency. The effect of subsequent administration of pteroyl glutamic acid (PGA) on these changes induced by Apt was also studied. These studies may contribute to the elucidation of the pathophysiological condition associated with a low blood folic acid level as well as of the mechanisms of folic acid activities. This communication concerns the clinical picture obtained in these studies.
\end{abstract}

\section{EXPERIMENTAL}

\section{Test Subjects.}

Two healthy volunteers living in the University Hospital were subjected 
to the present study. In each subject two series of the experiments were conducted, one in summer (August-October) and the other in winter (December -April). These will be described as Cases 1 to 4 for convenience' sake.

2. Experimental Methods.

The magnesium salt of Apt synthetized by Uyeo (10) was used in the present study. Its potent anti-folic acid activity had been microbiologically verified by Eguchi (11) using Lactobacillus casei.

3. Dosage and Duration of Administration.

The administration of Apt was at first started with a subcutaneous dose of $0.005 \mathrm{mg} / \mathrm{kg}$ daily, and if there was no serious response of the blood folic acid level the dose was increased and continued until certain constant findings were obtained (Table I). The initial dose was based on the dose given for the

TABLE I

Dosage of Aminopterin.

\begin{tabular}{|c|c|c|c|c|c|}
\hline Case & $\begin{array}{l}\text { Age } \\
\text { Sex }\end{array}$ & Weight & Dosage & $\begin{array}{l}\text { Total } \\
\text { dosage }\end{array}$ & $\begin{array}{l}\text { Treatment after } \\
\text { withdrawing } \\
\text { aminopterin }\end{array}$ \\
\hline 1 & $\begin{array}{c}30 \\
\text { female }\end{array}$ & $\begin{array}{l}k g \\
58\end{array}$ & $\begin{array}{l}\text { mg/kg/day } \\
0.005 \text { for the first } 14 \text { days } \\
0.01 \text { for the following } 56 \text { days }\end{array}$ & $\begin{array}{c}m g \\
36.5\end{array}$ & $\begin{array}{l}\text { PGA } 90 \mathrm{mg} \\
\text { daily for } 20 \text { days }\end{array}$ \\
\hline 2 & $\begin{array}{c}24 \\
\text { female }\end{array}$ & 52 & The same as the above & 32.8 & None \\
\hline 3 & $\begin{array}{c}31 \\
\text { female }\end{array}$ & 63 & $\begin{array}{l}0.01 \text { for the first } 70 \text { days } \\
0.013 \text { for the following } 30 \text { days }\end{array}$ & 68.7 & $\begin{array}{l}\text { PGA } 90 \mathrm{mg} \\
\text { daily for } 20 \text { days }\end{array}$ \\
\hline 4 & $\begin{array}{c}25 \\
\text { female }\end{array}$ & 55 & $\begin{array}{l}0.01 \text { for the first } 70 \text { days } \\
0.013 \text { for the following } 20 \text { days } \\
0.015 \text { for the last } 20 \text { days }\end{array}$ & 69.3 & $\begin{array}{l}\text { The same as the } \\
\text { above }\end{array}$ \\
\hline
\end{tabular}

treatment of leukemias ( 1 to $2 \mathrm{mg}$ daily) and on the blood folic acid levels in leukemic patients (approximately twice as high as the normal).

Cases 1,3, and 4 received PGA immediately after withdrawing Apt and their response to the PGA treatment was observed, while Case 2, as a control, received no PGA treatment. The daily dose of PGA was $90 \mathrm{mg}$ given intramuscularly (110 to 150 times as much as the daily dose of Apt). This dose was based on the animal experiments suggesting that the dose of PGA re-

TABLE II

Content of the Diet (Calculated).

\begin{tabular}{lr|c} 
Total Calories & & 2300 \\
Protein & $(g)$ & $80-90$ (animal protein, 30-40) \\
Fat & $(g)$ & 30 \\
Vitamin A & (I.U.) & $4000-6000$ \\
Thiamine & $(\boldsymbol{m g})$ & $0.8-1.0$ \\
Riboflavin & $(\boldsymbol{m g})$ & $0.7-0.8$ \\
Ascorbic acid & $(\boldsymbol{m g})$ & $90-100$
\end{tabular}


quired for its antagonistic action against Apt is 100 to 400 times as much as the dose of Apt given, although these figures are conflicting.

The regular hospital ration was given during the period of the present study. Its content is shown in Table II. More soy beans and green vegetables, however, were received in winter than in summer.

\section{RESULTS}

\section{General Symptoms.}

There were very few subjective symptoms in all the cases, but slight general malaise and anorexia appeared 10 to 20 days before the termination of the Apt administration. Concurrently the face looked dull and in the three cases except in Case 2 pallor and edema of the face were also observed.

It has been reported that the decarboxylation of dihydroxyphenyl-alanine is inhibited by folic acid antimetabolites (14) and that hyperpigmentation of the skin due to melanogenesis may appear in patients with severe acute leukemia treated with Apt (15). In the present study, however, such skin manifestations as pigmentation, exanthema, and loss of hair, except for diminshed lustre of the skin, were negative in all the cases.

\section{Gastrointestinal System.}

The earliest and most marked among the gastrointestinal symptoms were such lesions in the oral cavity as painful ulcerations on the oral mucosa especially on the lips and as specific lesions of the tongue and gingivae.

Lesions of the Tongue The lesions of the tongue became apparent the earliest. Reddening and hypertrophy of the lingual papillae occurred about 20 days after starting the Apt administration, beginning at the tip and sides of the tongue and gradually spreading along the sides toward the root. Concurrently the tongue became diffusely swollen and purplish red in colour and had dental impressions. Later developed gradually such manifestations as atrophy of the papillae at the tip, hemorrhagic tendency in the papillae, and increased lingual fissures. Case 4 had a rice-corn-sized hemorrhagic ulcer at the edge of the tongue after receiving Apt for about 100 days.

Lesions of the Gingivae - The lesions of the gingivae occurred somewhat later than those of the tongue. Infiltrations, light purplish red in colour, appeared at the edges of the gingivae in about 30 days following the initiation of the experiment, being gradually intensified in their colour and degree until a part of them became hemorrhagic.

Lesions of the Lips and Oral Mucosa - The lesions of the lips and oral mucosa made their appearance still later. In the later period of the Apt administration, $\boldsymbol{i} . \boldsymbol{e}$, 20 to 30 days before withdrawing Apt, rice-corn-sized injections and infiltrations were visible on the lips and on the oral mucosa, especially in the regions opposite the teeth. These infiltrations gradually enlarged and merged together. Those on the lips became hemorrhagic and finally formed painful ulcers (Fig. 1).

Although these lesions of the tongue, lips and oral mucosa somewhat resemble those occurring in riboflavine (16) or pyridoxine deficiency (17) or in 
pellagra, the blood riboflavin and cozymase levels were normal throughout the period of the Apt administration. Different from these conditions was also the failure in the present study to note angular stomatitis and circumcorneal hyperemia.

Appetite, etc. - Appetite was well preserved at first, but slight anorexia was complained of in all the four cases in the later period of the Apt administration. Case 3 passed poorly formed dyspeptic stools containing a little mucus ( 2 or 3 stools a day) for the last 2 days of the Apt

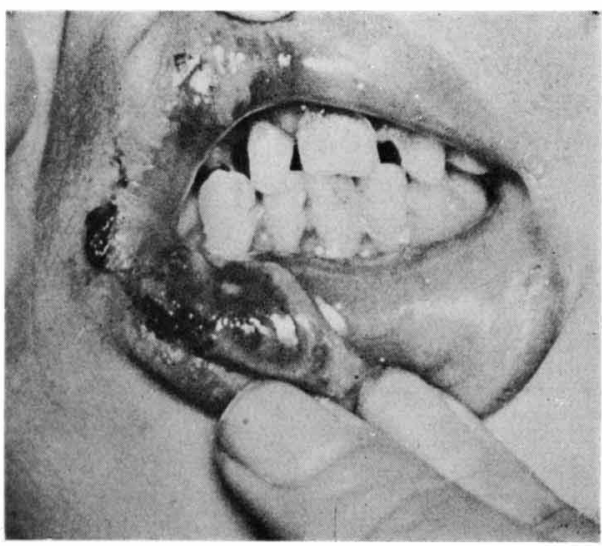

FIg. 1 Lesion of the Lip. administration. Nausea, vomiting, abdominal pain, and occult blood in the stool, however, were absent.

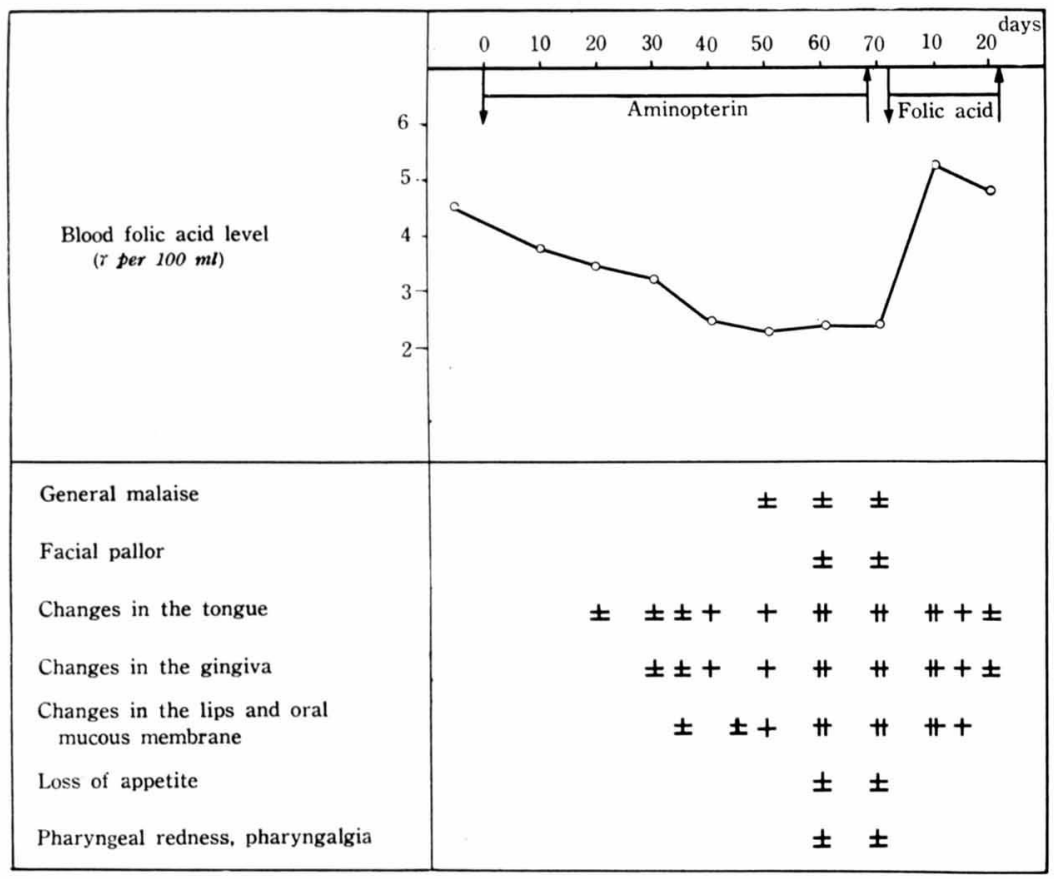

FIG. 2

The reports that lesions of the intestinal mucosa including congestion, edema, and desquamation were observed in animals receiving Apt may possibly explain the occurrence of the diarrhea noted in Case 3. 


\section{Cardiovascular System.}

No significant findings in heart sounds and blood pressure were obtained, except for the venous hum audible in the three cases except in Case 1 in the later period of the Apt administration.

\section{Respiratory System.}

Although pulmonary edema has been reported to occur in rabbits given Apt (25), there was no evidence of such a condition in the presnet study. However, pharyngeal pain and injection as well as common cold tended to be more frequently encountered in the later period of the Apt administration. High fever (about $39.5^{\circ} \mathrm{C}$ ) occurred twice in Case 4 , but the temperature returned to normal in 1 or 2 days following a penicillin injection (300,000 units).

\section{Genitourinary System.}

Menstrual disturbances such as irregularity and hypomenorrhea occurred with the exception of Case 1 in the later period of the Apt administration. These disturbances may be somewhat explicable from the works that the response of the sex glands to sex hormones is decreased in animals receiving Apt as well as in those fed a folic acid-deficient diet (21).

Neither polyuria nor oliguria was observed. No chemical changes in the urine were noted except for an increase in urinary urobilinogen and for qualitative and quantitative changes in urinary amino acids, as will be described in later communications from this institution. The microscopic findings of the urine were also normal.

\section{Other Manifestations.}

Loss of weight, disturbances of sleep, and visual and auditory disorders failed to occur. Abnormalities of deep reflexes, sensory and motor disturbances, and Romberg's sign were likewise negative. Some loss of memory, however, was noted in Case 3 in the later period of the Apt administration.

\section{Recovery of the Manifestations after Discontinuing the Administration of Apt.}

Those manifestations described above gradually disappeared after discontinuing the administration of Apt. This recovery, however, was much more rapid in the cases where the administration of folic acid was started immediately after withdrawing Apt than in the control (Case 2). Following the folic acid administration the appetite improved and the face looked lively in 24 hours. The general malaise and abnormal stools were relieved in 2 to 3 days. The pallor of the face, the venous hum as well as the lesions of the lips and oral mucosa almost disappeared in 7 days. On the other hand, the lesions of the tongue and gingivae which had appeared earlier, failed to respond as rapidly. Especially the tongue lesions recovered almost as slowly even in the cases given folic acid as in the control.

\section{DISCUSSION}

The chief manifestations observed in healthy human subjects receiving Apt for a prolonged period of time were shown to include general malaise, gastrointestinal disturbances (anorexia and specific lesions of the lips, tongue, and 
gingivae), hemorrhagic tendency, diminished biological defense mechanisms, and menstrual disorders. These conditions were also verified by the laboratory findings to be given in later communications from this institution, $\boldsymbol{i}$. $\boldsymbol{e}$, reduced free hydrochloric acid and pepsin in gastric juice (20), lowered phagocytic and migratory functions of the neutrophil leukocytes ${ }^{1}$, thrombocytopenia, and prolonged bleeding time. Furhermore, the additional laboratory examinations performed in this institution, provided the evidence for decreased hematopoietic function (macrocytic anemia, thrombocytopenia, diminished count and impaired maturation of the bone marrow cells (18)), impaired partial liver functions (lowered serum cholesterol ester ratio, reduced vitamin $\mathrm{A} /$ carotene ratio, increased urobilinogenuria ${ }^{1}$ ), and disturbed protein metabolism (abnormal aminoaciduria involving tyrosine, lysine, and leucine as detected by paper chromatography (26), reduced serum albumin, increased serum euglobulin and non-protein nitrogen ${ }^{1}$ ).

In the present study, two series of similar experiments were conducted in two and the same individuals at an interval of about 50 days, although described as four cases for convenience' sake. A comparative observation between the first and the second series of the experiments conducted in summer and in winter respectively showed that, though similar manifestations occurred in both, their appearance was generally more retarded in the second series. The reason for this is not clear, but this may possibly have resulted from the facts that vegetables such as spinaches and soy beans rich in folic acid (12) were received in larger amounts in winter and that in contrast to other B-group vitamins the excretion of folic acid in the sweat is several times as much as that in the urine in hot weathers (19).

That the occurrence of those chief manifestations described above together with the blood picture and other laboratory findings to be reported later, is closely related to a disturbance of folic acid metabolism caused by administration of Apt is evident from the following facts: first, a certain relationship was observed between the date of noting those manifestations as well as their intensity and the reduction in blood folic acid, and moreover, most of those manifestations were relieved by PGA, given after withdrawing Apt, much more rapidly than in a control; secondly, the PGA loading tests performed prior to, and immediately after, the prolonged Apt administration as well as after the use of PGA, disclosed that the Apt administration resulted in a PGA metabolism disturbance similar to that observed in patients who responded to PGA; and thirdly, there was a great similarity between those manifestaions resulting from Apt administration and those appearing in animals fed a folic acid-deficient diet.

\section{SUMMARY}

1. Experimental folic acid deficiency was induced in man by administration of aminopterin.

\footnotetext{
${ }^{1}$ To be published later.
} 
2. Changes in the digestive, cardiovascular, and genital systems were observed.

3. These changes generally responded to PGA treatment rapidly.

\section{ACKNOWLEDGEMENT}

The help of Professor Shojiro Uyeo, Pharmaceutical Department, Osaka University, who most generously provided the samples of aminopterin, is gratefully acknowledged. This study was aided by a grant from the Scientific Research Fund of the Ministry of Education.

\section{REFERENCES}

1. Seeger, D. R., Smith, J. M., Jr., and Hultquist, M. E., J. Am. Chem. Soc. 69, 2567 (1947) ; Seeger, D. R., Cosulich, D. B., Smith, J. M., Jr., and Hultquist, M. E., ibid. 71, 1753 (1949).

2. Pollack, M. A., Taylor, A., and Williams, R. G., Univ. Texas Pub. (4237), 56 (1942), quoted by (8).

3. Bethell, F. H., and Swendseid, M. E., J. Clin. Invest. 25, 917 (1946).

4. Lewisohn, R., Leuchtenberger, A., Leuchtenberger, R., and Keresztesy, J. C., Science 104, 436 (1946).

5. Farber, S., Cutler, E. C., Hawkins, J. W., Harrison, J. H., Peirce, E. S., and Lenz, G. G., Science, 106, 619 (1947).

6. Farber, S., Blood 4, 160 (1949).

7. Berman, L., Axelrod, A. R., Vonder Heide, E. C., and Sharp, E. A., Am. J. Clin. Path. 19, 127 (1949).

8. Sacks, M. S., Bradford, G. T., and Schoenbach, E. B., Ann. Int. Med. 32, 80 (1950).

9. Smith, C. H., and Bell, W. R., Am. J. Dis. Child. 79, 1031 (1950).

10. Uyeo, S., Vitamins 3, 160 (1950).

11. Eguchi, R., ibid. 5, 325 (1952).

12. Olson, O. E., Burris, R. H., and Elvehjem, C. A., J. Am. Diet. Assoc. 23, 200 (1947).

13. Inouye, K., Takeuchi, T., Akaeda, S., Eguchi, R., Vitamins 4, 147 (1951).

14. Martin, G. J., and Beiler, J. A., J. Am. Pharm. Assoc. 37, 32 (1948).

15. Waisman, H. A., Richmond, J. B., and Zimmerman, A. A., Proc. Soc. Exptl. Biol. Med. 75, 332 (1950).

16. Sebrell, W. H,, and Butler, R. E.. Publ. Health Rep. 53, 2282 (1938).

17. Mueller, J. F., and Vilter, R. W., J. Clin. Invest. 29, 193 (1950).

18. Inouye, K., and Takeuchi, T., J. Vitaminology 2, (1956).

19. Welch, A. D., J. Biol. Chem. 155, 401 (1944).

20. Binehart, J. F., and Greenberg, L. D., Am. J. Pathol. 24, 710 (1948).

21. Hertz, R., Proc. Soc. Exptl. Biol. Med. 67, 113 (1948).

22. Sargent, F., New Engl. J. Med. 237, 667 (1947).

23. Jukes, T. H., and Stockstad, E. L., Physiol. Rev. 28, 51 (1948).

24. Woll, E., Arch. Pathol. 46, 559 (1948).

25. Minnich, V., Moore, C. V., Smith, D. E., and Elliott, G. V., Arch. Pathol. 50, 787 (1950).

26. Mori, H,. Vitamins 7, 389 (1954). 